\title{
Emprego do cloreto de polialumínio em estudos de tratabilidade de água de abastecimento via coagulação, floculação e sedimentação
}

\author{
Use of polyaluminium chloride in studies of water supply treatability \\ through coagulation, flocculation, and sedimentation
}

\section{Wagner Yukio Kamiwada' ${ }^{\circledR}$, Priscila Vega Andrade ${ }^{1}\left(\mathbb{0}\right.$, Adriano Gonçalves dos Reis $^{1 *}$ ([)}

\begin{abstract}
RESUMO
Cloreto de polialumínio (PAC) é um coagulante polimérico inorgânico préhidrolisado que tem se destacado no tratamento de água de abastecimento e residuária por formar um precipitado de $\mathrm{Al}(\mathrm{OH})_{3}{ }_{3}^{*}$ rígido e pesado, além de ter baixo efeito no pH. A literatura, porém, ainda é escassa na correlação da química e da física do coagulante com otimizações de processo. Nesse sentido, o objetivo deste trabalho foi empregar o PAC em estudos de tratabilidade de água de abastecimento via coagulação, floculação e sedimentação. Para isso, inicialmente foi feito um modelamento matemático para ajuste de turbidez e pH e construídos diagramas de coagulação de turbidez e de cor aparente remanescentes com pH de 4,0 a 9,0 e dosagem de 10 a 120 mg..-1 de PAC (0,6 a 6,9 mg. $\mathrm{L}^{-1}$ de $\mathrm{Al}^{\mathrm{\beta}+}$ ). Também foram estudados diferentes gradientes de velocidade e tempos de mistura para a coagulação e a floculação. Os diagramas de coagulação apresentaram resultados satisfatórios na faixa de $\mathrm{pH}$ entre 7 e 9 com dosagem superior a $30 \mathrm{mg}^{\mathrm{L}} \mathrm{L}^{-1}$ de PAC $\left(1,7 \mathrm{mg} \cdot \mathrm{L}^{-1}\right.$ de $\mathrm{A}^{(3+)}$, e está relacionado com a solubilidade mínima do $\mathrm{Al}(\mathrm{OH})_{3}{ }^{*}$. Otimizações da coagulação e da floculação obtiveram melhora de até 79\% da turbidez remanescente, redução de até 83\% da área do sedimentador ou redução de até $67 \%$ na dosagem de PAC, em razão de um aumento do tamanho do floco produzido. Um conhecimento aprofundado da química e da física do processo relacionado ao uso do PAC pode, portanto, trazer benefícios ao seu uso.
\end{abstract}

Palavras-chave: diagrama de coagulação; cloreto de polialumínio; PAC; otimização de processo.

\begin{abstract}
Polyaluminium chloride (PAC) is a pre-hydrolyzed inorganic polymeric coagulant that is being used widely in the treatment of water supply and wastewater by forming a hard and heavy $\mathrm{Al}(\mathrm{OH})_{3}{ }^{*}$ precipitate, in addition to having a smaller effect on $\mathrm{pH}$. The literature, however, is still scarce in correlating the chemistry and physics of the coagulant with process optimizations. The objective of this paper is to use PAC in studies of water supply treatability through coagulation, flocculation, and sedimentation. For this purpose, a mathematical modeling was initially performed to adjust turbidity and $\mathrm{pH}$, and then remaining turbidity and apparent color coagulation diagrams were constructed with a pH of 4.0 to 9.0 and a dosage of 10 to $120 \mathrm{mg}^{\mathrm{L}^{-1}}$ of PAC (0.6 to $6.9 \mathrm{mg}^{-\mathrm{L}^{-1}}$ of $\mathrm{Al}^{{ }^{+}+}$). Different gradients of velocity and mixing times for coagulation and flocculation were also studied. The coagulation diagrams indicated satisfactory results in the $\mathrm{pH}$ range between 7 and 9 with a dosage higher than $30 \mathrm{mg} . \mathrm{L}^{-1}$ of $\mathrm{PAC}\left(1.7 \mathrm{mg} . \mathrm{L}^{-1}\right.$ of $\mathrm{Al}^{\mathrm{\beta}}$ ), and it is related to the minimum solubility of $\mathrm{Al}(\mathrm{OH})_{3}{ }_{3}^{*}$. Coagulation and flocculation optimizations achieved an improvement of up to $79 \%$ in the remaining turbidity, a reduction of up to $83 \%$ in the settler area or a reduction of up to $67 \%$ in PAC dosage, due to an increase in the size of the floc produced. An in-depth knowledge of the chemistry and physics of the process related to the use of PAC can, therefore, bring benefits to its use.
\end{abstract}

Keywords: coagulation diagram; polyaluminium chloride; PAC process optimization.

\section{INTRODUÇÃO}

Nas estações de tratamento de água (ETAs) de abastecimento no Brasil, a tecnologia mais utilizada é a do tipo ciclo completo, que consiste nas operações unitárias de coagulação, floculação, sedimentação (ou flotação) e filtração, seguidas pela desinfecção, fluoração e estabilização final (DI BERNARDO; DANTAS, 2005). Para que o tratamento resulte em um bom desempenho é fundamental que a coagulação seja eficiente. O bom funcionamento dessa primeira etapa está diretamente relacionado ao sucesso das operações posteriores. Dessa forma, estudos mais aprofundados são imprescindíveis para uma correta seleção do coagulante e para uma seleção da sua dosagem e do pH ideal para sua utilização (GHERNAOUT et al., 2015). 
A coagulação consiste na adição do coagulante na água para desestabilizar as partículas suspensas no meio, sendo estas coloides carregados negativamente em sua superfície. A desestabilização ocorre pela reação de hidrólise, ao se adicionar o coagulante na água, e pela adsorção dessas espécies hidrolisadas à superfície das partículas coloidais. Esse processo pode ser classificado em quatro principais mecanismos, dependendo da dosagem do coagulante e das condições físico-químicas da água: a compressão da dupla camada elétrica; a adsorção e neutralização de cargas; a varredura; e a adsorção e formação de pontes; que podem atuar individualmente ou de forma conjunta. Nas ETAs, comumente, prioriza-se o mecanismo de varredura para tratar a água, no qual há a maior adição de coagulante nesse meio e a formação de precipitados. Essa preferência ocorre pelo fato de esses precipitados serem maiores do que aqueles formados por outros mecanismos, resultando em uma velocidade de sedimentação maior (BARTIKO; DE JULIO, 2015; DI BERNARDO; DANTAS, 2005).

Atualmente, uma pressão tem sido feita no intuito de se otimizar as operações unitárias de coagulação, floculação e sedimentação com o objetivo de maximizar a remoção de partículas e a consequente turbidez remanescente, minimizar a produção de lodo e reduzir os custos de operação (PERNITSKY; EDZWALD, 2006).

Assim, para auxiliar uma ETA a obter seus parâmetros ideais nos processos do ciclo completo, estudos de tratabilidade em laboratório são realizados, variando a dosagem do coagulante a ser estudado, o pH do meio, os gradientes de velocidade médios e os tempos de mistura. Para facilitar esses ensaios, comumente se utiliza o equipamento jar test, no qual são realizados os processos e as operações de coagulação, floculação e sedimentação (FERRARI et al., 2012).

Com os resultados obtidos, é possível construir diagramas de coagulação, que consistem em curvas de isoeficiência de algum parâmetro de controle, sendo comumente utilizado o de turbidez e/ou de cor aparente remanescentes. Essa ferramenta ilustra graficamente quais serão as combinações de dosagens de coagulante e de pH de coagulação que resultarão em determinada turbidez remanescente (BARTIKO; DE JULIO, 2015; FERRARI et al., 2012).

Os coagulantes mais utilizados nas ETAs do Brasil são sais de ferro ou alumínio, que hidrolisam rapidamente com a água e geram um precipitado amorfo do tipo $\mathrm{Fe}(\mathrm{OH})_{3}$ ou $\mathrm{Al}(\mathrm{OH})_{3}$. Recentemente, tem-se estudado o uso de coagulantes poliméricos orgânicos e inorgânicos em substituição, total ou parcial, aos coagulantes inorgânicos tradicionais (RIBEIRO; ANDRADE; REIS, 2019). Entre esses, o coagulante do tipo cloreto de polialumínio (PAC) é o mais comum e de maior disponibilidade no mercado nacional (HOWE et al., 2016; FERREIRA FILHO; WAELKENS, 2009). O PAC é produzido comercialmente pela reação controlada de sais de alumínio com uma base. Eles são caracterizados pelo seu grau de neutralização $(r)$, ou basicidade, conforme Equação 1:
$r=\left[\mathrm{OH}^{-}\right] /\left[\mathrm{Al}_{\mathrm{T}}\right]$

Em que:

$\left[\mathrm{OH}^{-}\right]$= base adicionada durante a produção;

$\left[A l_{\mathrm{T}}\right]=$ alumínio total disponível.

A basicidade também pode ser calculada em \%, conforme Equação 2:

basicidade $=(r / 3) \times 100$

$\mathrm{O}$ valor de $r$ pode variar de 0 a 3 , correspondendo à basicidade de 0 a 100\%. PACs comerciais são normalmente disponíveis na basicidade entre 15 e $85 \%$, sendo acima de $60 \%$ considerado alta basicidade. A basicidade afeta o consumo de alcalinidade do coagulante, bem como a prevalência da formação de espécies poliméricas ou monoméricas. A termodinâmica da formação de espécies dissolvidas de $\mathrm{Al}$, bem como o precipitado amorfo de $\mathrm{Al}(\mathrm{OH})_{3}$, são altamente dependentes do pH do meio (PERNITSKY; EDZWALD, 2003; 2006; WEI et al., 2015; ZHANG et al., 2017).

O precipitado de $\mathrm{Al}(\mathrm{OH})_{3}$ formado pela adição de PAC tem sido reportado pela literatura como diferente do formado pela adição de sulfato de alumínio, pois a estrutura polimérica do PAC é mantida em seu precipitado. Por esse motivo, o precipitado formado pelo PAC é designado como $\mathrm{Al}(\mathrm{OH})_{3}{ }^{*}$, para diferenciar do precipitado formado pelo sulfato de alumínio (PERNITSKY; EDZWALD, 2003; 2006). Esses precipitados são rígidos e pesados, propiciando o aumento da velocidade de sedimentação. Outros benefícios associados ao uso de PAC são o baixo efeito no $\mathrm{pH}$ em razão da basicidade presente, a menor quantidade de alumínio residual na água e a floculação mais rápida (HOWE et al., 2016; FERREIRA FILHO; WAELKENS, 2009; PERNITSKY; EDZWALD, 2003).

Embora o coagulante PAC esteja atualmente em uso para o tratamento de água de abastecimento e água residuária, a literatura ainda é muito escassa na correlação existente entre a química e física do coagulante e as otimizações de processo. Nesse contexto, o objetivo deste estudo foi otimizar as operações de coagulação, floculação e sedimentação com o uso do coagulante PAC correlacionando com o pH, o tamanho e a morfologia de partícula e o mecanismo dominante de coagulação para o tratamento de água de abastecimento.

\section{METODOLOGIA}

A água de estudo foi coletada no poço do Parque Tecnológico de São José dos Campos, antes de passar por qualquer tipo de tratamento, e os seguintes parâmetros foram analisados: $\mathrm{pH}$, alcalinidade (método potenciométrico) e temperatura, determinados com o auxílio do pHmetro Lucadema Luca 210 e de um agitador magnético DiagTech DT $3110 \mathrm{H}$; 
a turbidez, determinada pelo turbidímetro Policontrol AP2000; a cor aparente, por meio do colorímetro Policontrol AquaColor Cor; e a condutividade, por meio do condutivímetro Digimed DM-32.

Para ajuste da turbidez foi utilizada uma suspensão de caulinita em uma concentração de 50 g.L. $\mathrm{L}^{-1}$, preparada conforme Yukselen e Gregory (2004). O coagulante utilizado no estudo foi o PAC, com 10,91\% de $\mathrm{Al}_{2} \mathrm{O}_{3}$, basicidade livre de $62,38 \%(r=1,9)$ e densidade de 1,260 g.cm $\mathrm{cm}^{-3}$ a $25^{\circ} \mathrm{C}$. Como se trata do tratamento de água em escala de bancada, o coagulante foi diluído na concentração de 1,5\% p.

A distribuição do tamanho de partículas foi feita com o Cilas 1190, mantendo o agitador desligado durante a análise, que foi feita em triplicata. A morfologia dos flocos foi realizada com o estereoscópio Stereo Discovery V20 da ZEISS. A distribuição do potencial zeta foi medida com o Litesizer $^{\text {rux }} 500$ da Anton Paar. Para os ensaios de coagulação, floculação e sedimentação utilizou-se um jart test da PoliControl modelo FlocControl III de 6 jarros.

\section{Procedimento de ensaio}

Águas coletadas em tambores de $50 \mathrm{~L}$ eram ajustadas com solução de caulinita para uma turbidez média de 25 unT, que representa uma água de baixa turbidez, normalmente estudada por outros autores (BARTIKO; DE JULIO, 2015; CARVALHO et al., 2016; FARHADI; TAKDASTAN; BAGHBANY, 2016), para remoção via coagulação, floculação e sedimentação. Ao todo foram feitas 13 coletas. Para esse processo, realizou-se um estudo prévio com a água a ser tratada adicionando-se a solução de caulinita de $0,1 \mathrm{em} 0,1 \mathrm{~mL}$ em $1 \mathrm{~L}$ de água até atingir a turbidez superior a 25 unT. Com base nesse estudo, determinou-se a dosagem necessária de caulinita, com base na turbidez inicial, para se atingir o valor-alvo de 25 unT.

Os parâmetros dos processos e operações unitárias dos ensaios para a construção do diagrama de coagulação foram: gradiente de velocidade médio de mistura rápida $\left(G_{\mathrm{mr}}\right)$ de $1.200 \mathrm{~s}^{-1}$ e tempo de mistura rápida $\left(t_{\mathrm{mr}}\right)$ de $30 \mathrm{~s}$; gradiente de velocidade médio de floculação $\left(G_{\mathrm{fl}}\right)$ de $20 \mathrm{~s}^{-1}$ e tempo de floculação $\left(t_{\mathrm{fl}}\right)$ de $20 \mathrm{~min}$; e velocidade crítica de sedimentação $\left(v_{\mathrm{cs}}\right)$ de $0,5 \mathrm{~cm} \cdot \mathrm{s}^{-1}(14 \mathrm{~min})$. Esses parâmetros foram definidos como referência por estarem dentro de uma faixa normalmente utilizada (HOWE et al., 2016; HENDRIKS, 2011) quando o mecanismo de coagulação dominante é o de varredura, que é o mecanismo pretendido neste estudo. A temperatura da água sintética durante os ensaios foi de $23,3 \pm 1,2^{\circ} \mathrm{C}$. Para a construção dos diagramas de coagulação, formaram-se os pares de dosagem de coagulante e $\mathrm{pH}$ de coagulação, sendo a variação da dosagem de coagulante entre os valores de 10 e 120 mg.L $\mathrm{L}^{-1}$, e o $\mathrm{pH}$, na faixa de 4 a 9. No final de cada ensaio, realizou-se a medição da turbidez e da cor aparente remanescentes, além do $\mathrm{pH}$ e da temperatura. A variação do $\mathrm{pH}$ foi realizada por meio da adição de $\mathrm{NaOH} 0,1 \mathrm{~N}$ ou $\mathrm{HCl} 0,1 \mathrm{~N}$. Para determinar a dosagem de ácido ou base a ser adicionada na água para varrer o $\mathrm{pH}$ de 4 a 9 realizou-se também um estudo prévio, medindo-se a alcalinidade inicial e avaliando-se a variação do $\mathrm{pH}$ ao adicionar de $0,1 \mathrm{em} 0,1 \mathrm{~mL}$ de ácido (até $\mathrm{pH} 4,0$ ) e base (até $\mathrm{pH}$ $9,0)$ em $1 \mathrm{~L}$ de água. Quantificou-se também o efeito no $\mathrm{pH}$ em razão da adição de coagulante na dosagem de 10 a 120 mg.L $\mathrm{L}^{-1}$, adicionando-se PAC de 10 em 10 mg.L $\mathrm{L}^{-1}$ em $1 \mathrm{~L}$ de água. Com esses estudos iniciais, determinou-se a dosagem de $\mathrm{NaOH} 0,1 \mathrm{M}$ ou $\mathrm{HCl} 0,1 \mathrm{M}$, para cada dosagem de $\mathrm{PAC}$, necessária para varrer o $\mathrm{pH}$ de 4 a 9.

Assim, com os ensaios realizados, construiu-se os diagramas de coagulação, um com os valores de turbidez e outro com os valores de cor aparente remanescente, nos quais as linhas delimitam as regiões dos pares de dosagem de coagulante versus $\mathrm{pH}$ de coagulação que possuem turbidez/cor menor ou igual à indicada pela curva.

Depois de montados os diagramas, selecionou-se uma combinação de dosagens de produtos químicos com o melhor resultado (incluindo baixo consumo de matéria-prima e turbidez/cor remanescente) e iniciou-se os ensaios de otimização. Nos ensaios de otimização, foram analisados a eficiência - por meio da medição da turbidez e da cor remanescente -, o pH e a temperatura da água de estudo após todos os experimentos no jar test.

A otimização do $G_{\mathrm{mr}}$ e do $t_{\mathrm{mr}}$ consistiu em 3 ensaios, variando o $G_{\mathrm{mr}}$ com valores inferiores e superiores ao de referência $-600 \mathrm{~s}^{-1}$ (inferior), $1.200 \mathrm{~s}^{-1}$ (referência) e $1.500 \mathrm{~s}^{-1}$ (superior, sendo este o máximo que o jar test utilizado consegue operar) - e o $t_{\mathrm{mr}}$ de 5, 10, 15, 20, 25 e $30 \mathrm{~s}$. Com os resultados obtidos, construiu-se um gráfico de turbidez remanescente em função do $t_{\mathrm{mr}}$ para cada $G_{\mathrm{mr}}$, determinando qual combinação dos parâmetros apresentava menor utilização de recursos e turbidez remanescente ideal. Nessa etapa, os demais parâmetros de floculação e de sedimentação se mantiveram conforme aqueles definidos anteriormente.

Em seguida, realizou-se os ensaios de otimização da floculação, já com a coagulação otimizada, com $t_{\mathrm{fl}}$ de $5,10,15,20,25$ e 30 min e $G_{\mathrm{fl}}$

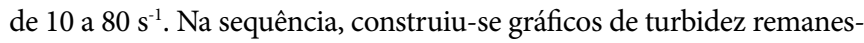
cente em função do $t_{\mathrm{fl}}$ de cada $G_{\mathrm{fl}}$. Nessa etapa de otimização, realizou-se interpolações dos gráficos construídos, de modo a obter os $G_{\mathrm{fl}}$ e os $t_{\mathrm{fl}}$ de uma floculação escalonada, conforme sugerido por Pádua (1994). A partir do gráfico, definiu-se o $G_{\mathrm{fl}}$ com melhor resultado em um $t_{\mathrm{fl}}$ de $5 \mathrm{~min}$; em seguida, determinou-se o segundo melhor $G_{\mathrm{fl}}$ partindo da turbidez obtida pela etapa anterior. Esse procedimento se repetiu até o minuto 20 ou até não ser identificada melhoria na turbidez.

A otimização da etapa de sedimentação ocorreu pela avaliação da $v_{\text {cs }}$ de 0,5 a $5 \mathrm{~cm} \cdot \mathrm{s}^{-1}$ com os parâmetros de coagulação e floculação otimizados. Para isso, efetuaram-se ensaios com tempos de sedimentação de 14,0; 7,0;4,7;3,5;2,3; e 1,4 min e construiu-se um gráfico de turbidez remanescente por $v_{c s}$, determinando aquele com maior $v_{c s} \mathrm{e}$ remoção de turbidez aceitável.

Por fim, realizou-se outro método de otimização, no qual se visou o limite de turbidez predeterminado e variou-se a dosagem de coagulante. 
Sendo assim, com a coagulação e a floculação otimizadas, executaram-se ensaios com diferentes dosagens e averiguou-se qual condição utilizava menos coagulante e, ao mesmo tempo, respeitava tal competência.

\section{RESULTADOS E DISCUSSÃO}

\section{Caracterização da água de poço e ajuste de pH e turbidez da água}

A Tabela 1 apresenta os valores obtidos na caracterização da água de poço do Parque Tecnológico de São José dos Campos.

Diante dos resultados apresentados na Tabela 1, observa-se que a água em estudo apresenta caráter levemente ácido e baixa alcalinidade. Como era esperado, os valores de turbidez e cor aparente foram baixos em razão da origem da água. Não houve variação expressiva na maioria dos parâmetros analisados. A baixa condutividade da água também evidencia a baixa presença de íons dissolvidos.

A Figura 1 apresenta o efeito da adição de solução de caulinita na água de estudo.

Com a linearização dos pontos apresentados na linha da Figura 1, obteve-se a Equação 3:

$D_{\text {caul }}=0,00298$. Turb $+0,00338$

Em que:

$D_{\text {caul }}=$ dosagem de solução de caulinita adicionada, em \%;

Turb $=$ turbidez encontrada da amostra, em unT.

Tabela 1 - Caracterização da água de poço utilizada no estudo.

\begin{tabular}{l|c|c|c|c}
$\begin{array}{l}\text { Turbidez } \\
(\text { unT) }\end{array}$ & $\begin{array}{c}\text { Cor aparente } \\
\text { (uC) }\end{array}$ & $\mathrm{pH}$ & $\begin{array}{c}\text { Alcalinidade } \\
\left(\mathrm{mg} \mathrm{CaCO}_{3} \mathrm{~L}^{-1}\right)\end{array}$ & $\begin{array}{c}\text { Condutividade } \\
\left(\mu \mathrm{S} . \mathrm{cm}^{-1}\right)\end{array}$ \\
\hline $0,19 \pm 0,10$ & $1,4 \pm 0,9$ & $6,87 \pm 0,13$ & $29,4 \pm 3,5$ & $69,93 \pm 5,49$ \\
\hline
\end{tabular}

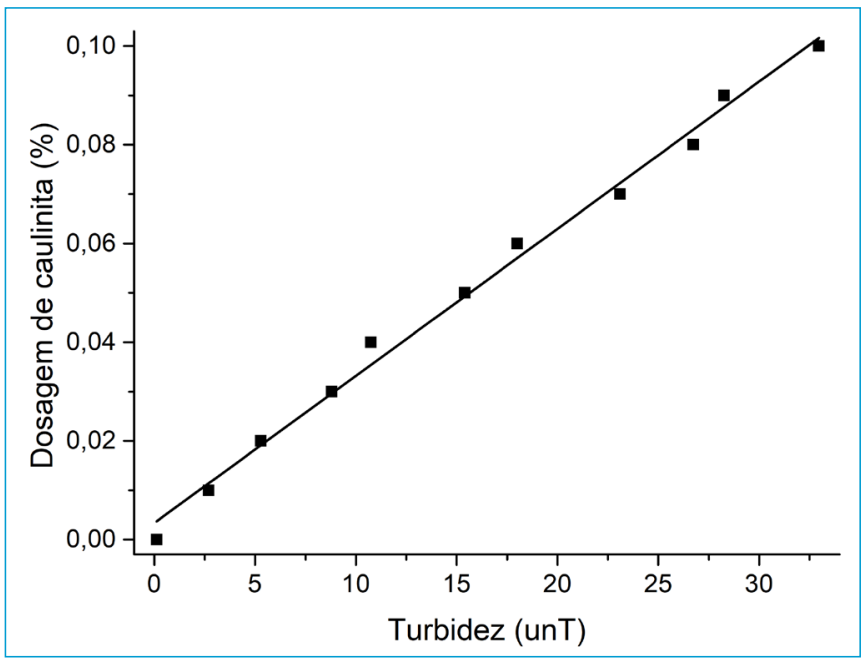

Figura 1 - Gráfico da variação de turbidez em função da dosagem (\%) de solução de caulinita adicionada.
O coeficiente de determinação $\left(\mathrm{R}^{2}\right)$ encontrado para a Equação 3 foi de 0,9929 .

Para determinação da dosagem de caulinita a ser adicionada em cada amostra de água do poço, utilizou-se a Equação 4:

$D_{\text {caul }}=\left[0,00298 .\left(\right.\right.$ Turb $_{\text {desej }}-$ Turb $\left.\left._{\text {med }}\right)+0,00338\right]$

Em que:

$D_{\text {caul }}=$ dosagem de solução de caulinita adicionada, em \%;

Turb $_{\text {desej }}=$ turbidez em estudo, correspondente a 25 unT;

Turb $_{\text {med }}=$ turbidez medida da amostra antes da adição de caulinita, em unT.

Com base na Equação 4, foi feito o ajuste das amostras da água de poço com a adição da solução de caulinita. A turbidez e a cor aparente da água sintética após os ajustes são apresentadas na Tabela 2. Os demais parâmetros da água apresentados na Tabela 1 não sofreram alteração após o ajuste com a caulinita.

A Figura 2 apresenta a distribuição do tamanho de partícula da água sintética produzida com solução de caulinita.

A distribuição do potencial zeta da água sintética e do PAC 1,5 \% p é apresentada na Figura 3.

Pelas Figuras 2 e 3A, observa-se que o tamanho de partícula em escala micrométrica, aliado ao potencial zeta negativo $(-22,1 \mathrm{mV}) \mathrm{da}$

Tabela 2 - Caracterização da água sintética utilizada no estudo.

\begin{tabular}{c|c} 
Turbidez (unT) & Cor aparente (uC) \\
\hline $25,3 \pm 0,7$ & $47,3 \pm 3,0$ \\
\hline
\end{tabular}

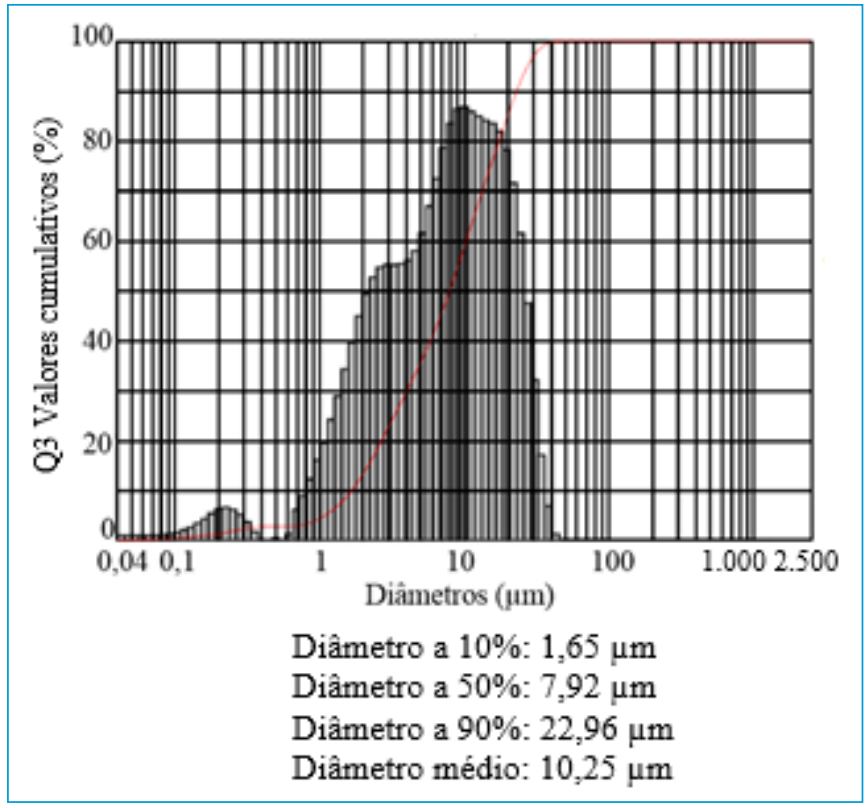

Figura 2 - Distribuição dos tamanhos de partícula da caulinita presente na água sintética. 
caulinita na água sintética, faz com que o mesmo esteja em estado coloidal estabilizado, evitando que a caulinita seja fisicamente separada da água em uma operação unitária de filtração, flotação ou sedimentação. Por outro lado, o potencial zeta positivo $(+38,5 \mathrm{mV})$ do PAC, apresentado na Figura 3B, permite que as cargas negativas do coloide sejam neutralizadas, além de, quando colocado em excesso e em condições ideais de $\mathrm{pH}$, poder formar o precipitado de $\mathrm{Al}(\mathrm{OH})_{3}{ }^{*}$ e realizar a coagulação por varredura.

Outra variável importante para a construção dos diagramas de coagulação é o $\mathrm{pH}$ durante a mistura rápida. Como o $\mathrm{pH}$ médio da água de estudo foi de $6,87 \pm 0,13$, para que se pudesse varrer o $\mathrm{pH}$ de 4 a 9 nos diagramas de coagulação foi avaliado o efeito no $\mathrm{pH}$ após adição de PAC e quantidade necessária de $\mathrm{NaOH} 0,1 \mathrm{M}$ ou $\mathrm{HCl} 0,1 \mathrm{M}$ na água de estudo para se atingir o $\mathrm{pH}$ desejado.

O PAC, apesar de apresentar um efeito no $\mathrm{pH}$ bem menor que os sais de ferro e alumínio por ser previamente hidrolisado (HOWE et al., 2016), também reduz o pH da água sintética, conforme apresentado na Figura 4.

O baixo efeito no $\mathrm{pH}$ com a adição de PAC, apesar da alcalinidade baixa da água sintética, deve-se à alta basicidade do PAC utilizado, que é de 62,38\%. O consumo de alcalinidade é inversamente proporcional à basicidade do PAC (PERNITSKY; EDZWALD, 2003; 2006). Com a linearização dos pontos apresentados na Figura 4, obteve-se a Equação 5:

$\Delta p H=-0,00613 . D_{\mathrm{PAC}}+0,02066$

Em que:

$\Delta p H=$ variação de $\mathrm{pH}$;

$D_{\text {PAC }}=$ dosagem de PAC adicionada, em mg. $\mathrm{L}^{-1}$.

O coeficiente de determinação $\left(R^{2}\right)$ encontrado para a Equação 5 foi de 0,99811 .
Para determinação da dosagem de soda cáustica ou ácido clorídrico a ser adicionado em cada jarro, calculou-se, inicialmente, a variação de $\mathrm{pH}$ desejado $\left(\Delta p H_{\text {dese }}\right)$ em função da dosagem de PAC, de acordo com a Equação 6:

$\Delta p H_{\text {desej }}=\mathrm{pH}_{\text {desej }}-\left[\mathrm{pH}_{\mathrm{med}}-0,00613 \cdot D_{\mathrm{PAC}}+0,02066\right]$

Em que:

$\Delta p H_{\text {desej }}=$ variação de $\mathrm{pH}$ desejada;

$\mathrm{pH}_{\text {desej }}=\mathrm{pH}$ desejado para o jarro em estudo;

$\mathrm{pH}_{\text {med }}=\mathrm{pH}$ medido da água de estudo.

Com base na Equação 6, caso a $\Delta p H_{\text {desej }}$ fosse positiva (necessidade de um aumento de $\mathrm{pH}$ ), adicionou-se soda cáustica; caso fosse negativa (necessidade de uma queda de $\mathrm{pH}$ ), adicionou-se ácido clorídrico.

A Figura 5 apresenta o efeito da adição de $\mathrm{NaOH} 0,1 \mathrm{M}$ ou $\mathrm{HCl}$ $0,1 \mathrm{M}$ na água de estudo.

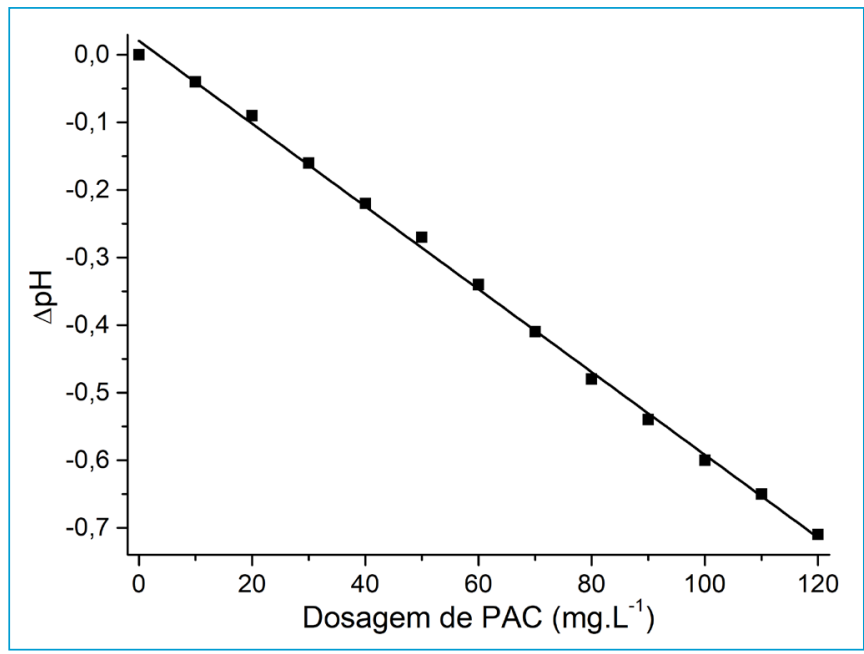

Figura 4 - Gráfico da variação de $\mathrm{pH}$ em função da dosagem de cloreto de polialumínio (mg.L-1).

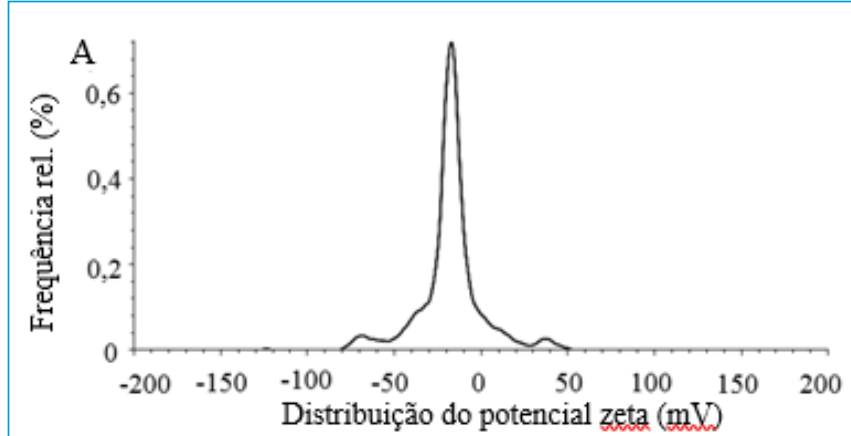

Potencial zeta médio: -22,1 mV

Desvio padrão: $\pm 0,4 \mathrm{mV}$ Mobilidade eletroforética: $-1,7242 \mu \mathrm{m} . \mathrm{cm} . \mathrm{V}^{-1} . \mathrm{s}$

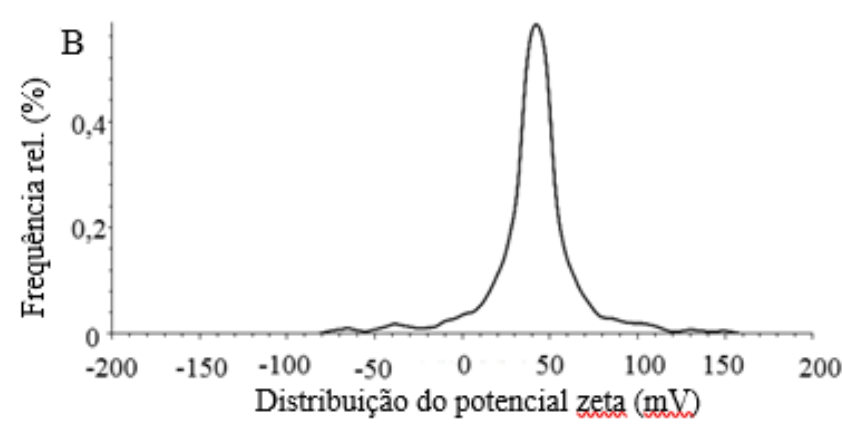

Potencial zeta médio: $+38,5 \mathrm{mV}$

Desvio padrão: $\pm 1,1 \mathrm{mV}$ Mobilidade eletroforética: $+3,0039 \mu \mathrm{m} . \mathrm{cm}^{\mathrm{i}} \mathrm{V}^{-1} \mathrm{~s}$

Figura 3 - Distribuição do potencial zeta da (A) água sintética com caulinita e do (B) cloreto de polialumínio 1,5 \% p. 
Com o ajuste polinomial dos pontos apresentados nas linhas das Figuras 5A e 5B, obtiveram-se as Equações 7 e 8, respectivamente:

$D_{\text {NaOH }}=0,07629 \cdot\left(\Delta p H_{\text {desej }}\right)^{3}-0,27769 \cdot\left(\Delta p H_{\text {dese }}\right)^{2}+0,37703 \cdot \Delta p H_{\text {desej }}-0,00259$

$D_{\mathrm{HCl}}=-0,07389 \cdot\left(\Delta p H_{\text {desej }}\right)^{3}-0,38714 \cdot\left(\Delta p H_{\text {dese }}\right)^{2}-0,75704 . \Delta p H_{\text {desej }}+0,00707$

Em que:

$D_{\mathrm{NaOH}}=$ dosagem de $\mathrm{NaOH}$ a ser adicionada, em \%;

$\Delta p H_{\text {desej }}=$ variação de $\mathrm{pH}$ desejada;

$D_{\mathrm{HCl}}=$ dosagem de $\mathrm{HCl}$ a ser adicionada, em $\%$.

Os coeficientes de determinação $\left(\mathrm{R}^{2}\right)$ encontrados para as Equações 7 e 8 foram de, respectivamente, 0,99722 e 0,99851.

Como a alcalinidade da água de estudo apresentou baixa variação $(29,4+3,5$ mg $\left.\mathrm{CaCO}_{3} \cdot \mathrm{L}^{-1}\right)$, as Equações 7 e 8 foram utilizadas para estimar as dosagens de ácido ou base para o correto acondicionamento da água de estudo.

\section{Diagramas de coagulação}

A Figura 6 apresenta os diagramas de coagulação construídos para a avaliação da remoção de turbidez e de cor aparente da água sintética.

Analisando a Figura 6, nota-se que a turbidez e a cor aparente remanescentes, respectivamente, nas Figuras 6A e 6B, reduzem gradativamente para $\mathrm{pHs}$ superiores a 6,5. Esse resultado é encontrado em razão do $\mathrm{pH}$ de solubilidade mínima reportada para o $\mathrm{Al}(\mathrm{OH})_{3}{ }^{*}$. Pernitsky e Edzwald $(2003 ; 2006)$ reportaram que para PAC com alta basicidade $(\mathrm{r}=2,1)$, a $20^{\circ} \mathrm{C}$, a solubilidade mínima é encontrada com $\mathrm{pH}$ de 6,4. Isso significa que para pHs menores que 6,4, o precipitado amorfo responsável pela coagulação no mecanismo de varredura $\left(\mathrm{Al}(\mathrm{OH})_{3}{ }^{*}\right)$ se encontra solúvel, não sendo eficiente, portanto, para remoção via sedimentação, pois os macroflocos não podem ser formados. O valor de turbidez remanescente recomendável após sedimentação para aumentar a duração das carreiras de filtração deve ser inferior a 2 unT (HENDRIKS, 2011). Os melhores resultados para esse limite de turbidez estavam na faixa de $\mathrm{pH}$
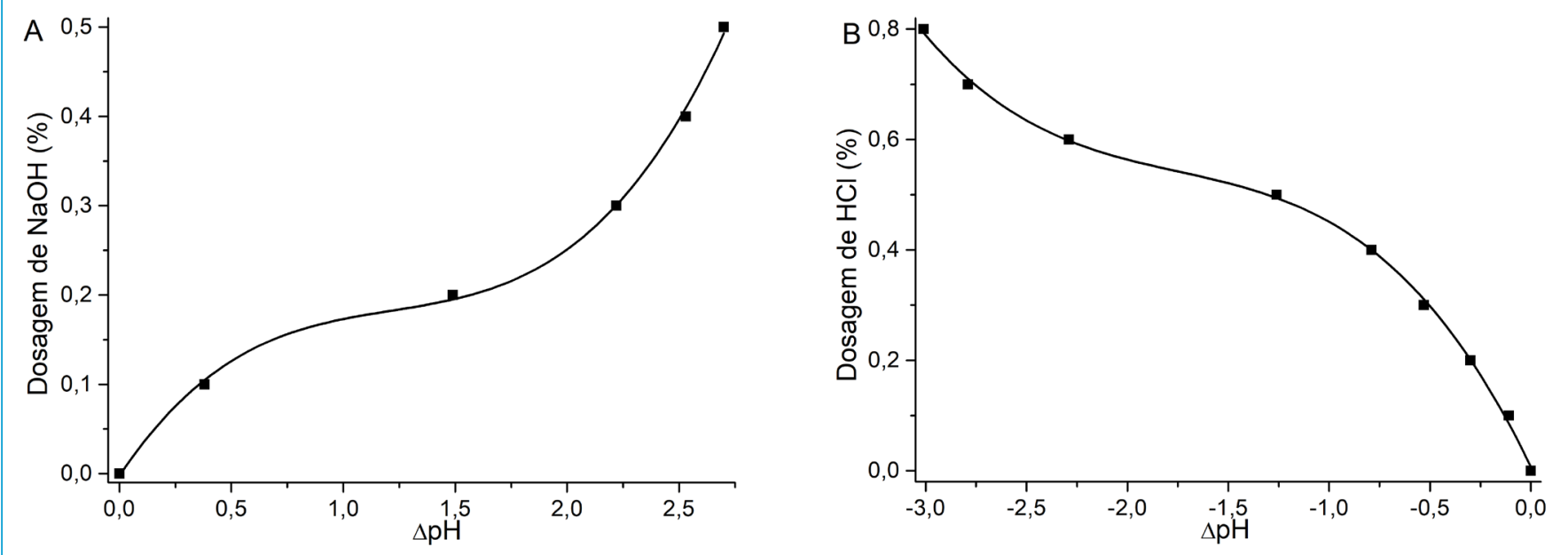

Figura 5 - Gráfico da variação de pH em função da dosagem (\%) de (A) $\mathrm{NaOH} 0,1 \mathrm{M}$ ou (B) HCl 0,1M.

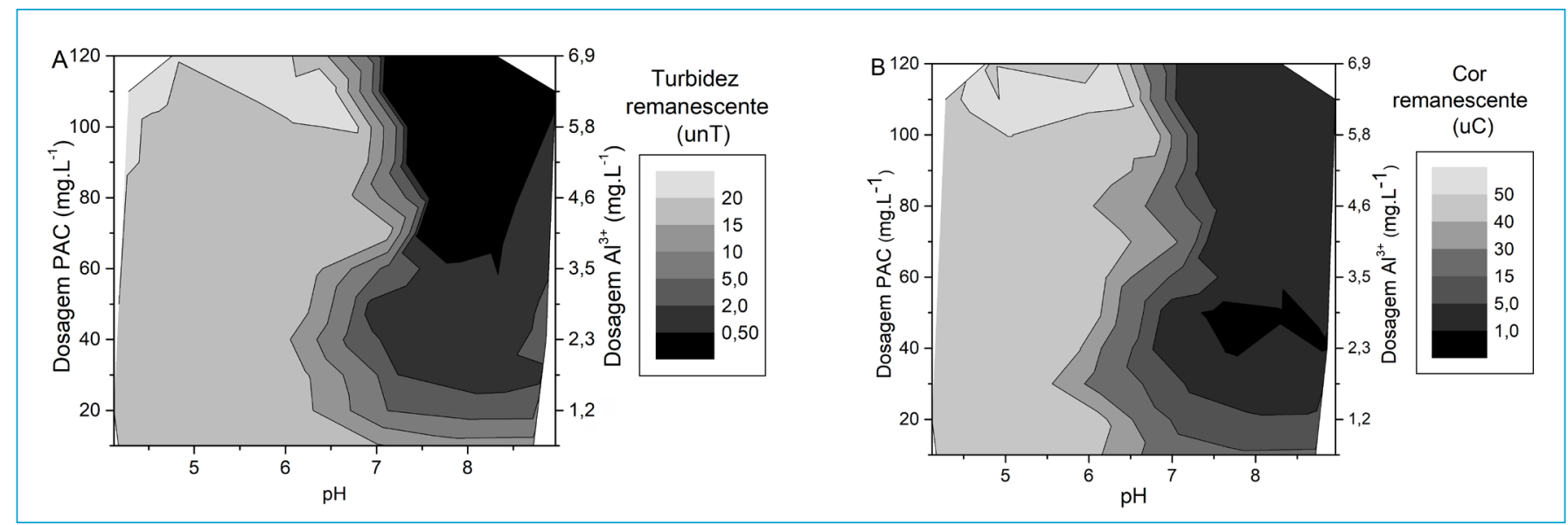

Figura 6 - Diagrama de coagulação em função da dosagem de cloreto de polialumínio (mg. $\left.L^{-1}\right)$ versus pH de coagulação para (A) turbidez remanescente (unT) e (B) cor aparente remanescente (uC). 
entre 7 e 9 com dosagem superior a $30 \mathrm{mg} \cdot \mathrm{L}^{-1}$ de PAC $\left(1,7 \mathrm{mg} \cdot \mathrm{L}^{-1}\right.$ de $\mathrm{Al}^{3+}$ ), caracterizando o mecanismo de coagulação de varredura como dominante. O padrão de potabilidade brasileiro (BRASIL, 2017) para turbidez $(<0,5 \mathrm{unT})$ e cor aparente $(<15 \mathrm{uC})$ pôde ser atingido para dosagens superiores a $60 \mathrm{mg} . \mathrm{L}^{-1}$ de PAC $\left(3,4 \mathrm{mg} . \mathrm{L}^{-1} \mathrm{de}\right.$ $\left.\mathrm{Al}^{3+}\right)$, não sendo necessário, neste caso, etapa posterior de filtração. Elevadas dosagens de coagulante, porém, não são uma alternativa viável para uso em uma ETA em razão dos custos com o coagulante e o agente alcalinizante requerido no tratamento, além da maior geração de lodo a ser tratado e disposto.

Dessa forma, visando a uma turbidez menor que 2 unT após sedimentação e ao menor consumo de matéria-prima, determinou-se a melhor combinação de dosagem de coagulante e de $\mathrm{pH}$, sendo este ponto composto de um $\mathrm{pH}$ de 7,0 e uma dosagem de $30 \mathrm{mg} . \mathrm{L}^{-1}$ de PAC $\left(1,7 \mathrm{mg} . \mathrm{L}^{-1} \mathrm{de} \mathrm{Al}^{3+}\right)$ com uma turbidez remanescente de 2,0 unT e cor aparente remanescente de 3,4 uC. A dosagem de solubilidade mínima em pH 7,0 reportada para o $\mathrm{Al}(\mathrm{OH})_{3}{ }^{*}$ é por volta de $0,9 \mathrm{mg} \cdot \mathrm{L}^{-1}$ de PAC (54 $\mu \mathrm{g} . \mathrm{L}^{-1}$ de $\mathrm{Al}^{3+}$ ) (PERNITSKY; EDZWALD, 2003; 2006), ou seja, muito inferior à dosagem ótima encontrada neste trabalho, que foi de $30 \mathrm{mg} . \mathrm{L}^{-1}$. Essa diferença se deve ao fato de que uma grande quantidade de macroflocos de $\mathrm{Al}(\mathrm{OH})_{3}{ }^{*}$ deve ser formada para que se tenha o efeito de varredura. Porém, melhorias de processo também podem diminuir essa diferença de dosagem. As próximas etapas deste estudo consistem na otimização das operações unitárias envolvidas para redução da turbidez remanescente ou do consumo de PAC, com base no par pH 7,0 e dosagem de 30 mg. $\mathrm{L}^{-1}$ de PAC (1,7 mg. $\mathrm{L}^{-1}$ de $\left.\mathrm{Al}^{3+}\right)$.

\section{Otimização da coagulação}

Os resultados obtidos na etapa de otimização da coagulação estão ilustrados na Figura 7.

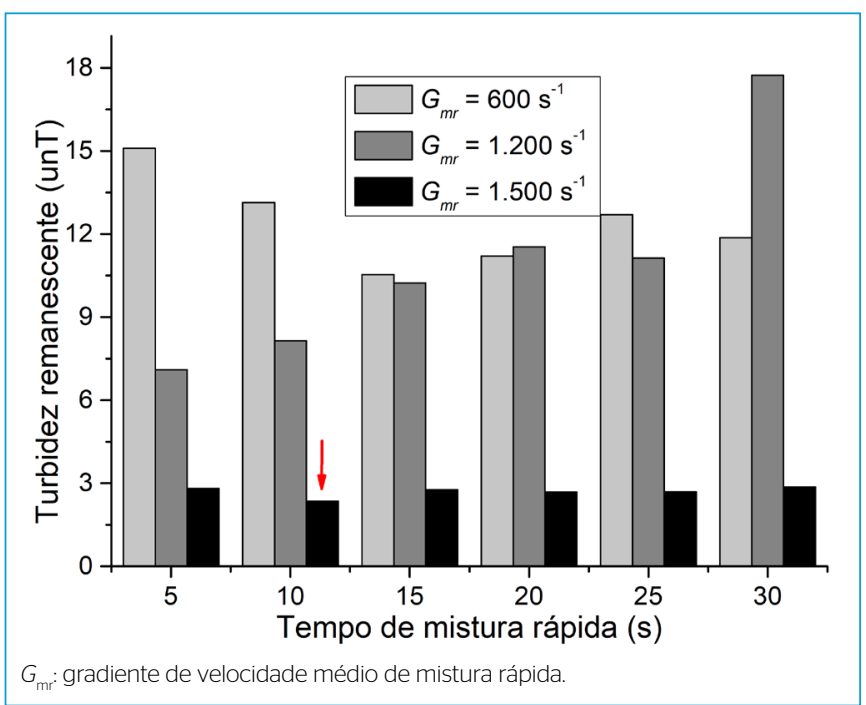

Figura 7 - Gráfico da variação da turbidez remanescente em função do tempo de mistura rápida para diferentes gradientes de velocidade médios de mistura rápida.
De acordo com a Figura 7, os melhores resultados foram obtidos com o $G_{\mathrm{mr}}$ de $1.500 \mathrm{~s}^{-1}$ e o $t_{\mathrm{mr}}$ de $10 \mathrm{~s}$, definindo essa combinação como o ótimo do tratamento. Observa-se que o maior $G_{\mathrm{mr}}$ resultou em melhores resultados. A energia introduzida deve ser capaz de romper a dupla camada, possibilitando que as partículas hidrolisadas possam se aderir à superfície dos coloides. Essas colisões são induzidas pela presença desse gradiente de velocidade na água, em que a frequência de choques por unidade de volume é proporcional ao $G_{\mathrm{mr}}$ à concentração das partículas suspensas e à dimensão das partículas. Sendo assim, pode-se afirmar que o maior $G_{\mathrm{mr}}$ possibilitou melhor desestabilização e, consequentemente, melhores resultados. $\mathrm{O} t_{\mathrm{mr}}$ porém, não foi uma variável com grandes alterações no resultado quando utilizado o maior $G_{\mathrm{mr}}$. O tempo de hidrólise e formação dos precipitados leva menos de $1 \mathrm{~s}$ (GHERNAOUT et al., 2015). No caso deste estudo, os $10 \mathrm{~s}$ foram suficientes para se atingir o melhor resultado.

\section{Otimização da floculação}

A Figura 8 ilustra o gráfico construído com os resultados dos ensaios de otimização da floculação, já com a coagulação otimizada. Nesta figura, observa-se que para o menor $G_{\mathrm{fl}}$ em estudo $\left(10 \mathrm{~s}^{-1}\right)$ há uma redução constante da turbidez remanescente com o $t_{\mathrm{fl}}$, passando de 19,9 unT após 5 min de floculação para 2,97 unT após 30 min de floculação. Por outro lado, para o maior $G_{\mathrm{fl}}$ em estudo $\left(80 \mathrm{~s}^{-1}\right)$, após $5 \mathrm{~min}$ a turbidez já reduziu para 1,18 unT, atingindo seu menor valor (0,43 unT) após $15 \mathrm{~min}$ de floculação. Porém, após este $t_{f}$, a turbidez remanescente começou a gradualmente aumentar, chegando a 1,22 unT após $30 \mathrm{~min}$. A taxa de ligação (floculação) de partículas é uma função da concentração das partículas e da frequência de colisão (GHERNAOUT et al., 2015). Isso explica o fato de que um maior $G_{\text {fl }}$ impõe uma maior frequência de colisão, e, com isso, os resultados imediatos de remoção de turbidez

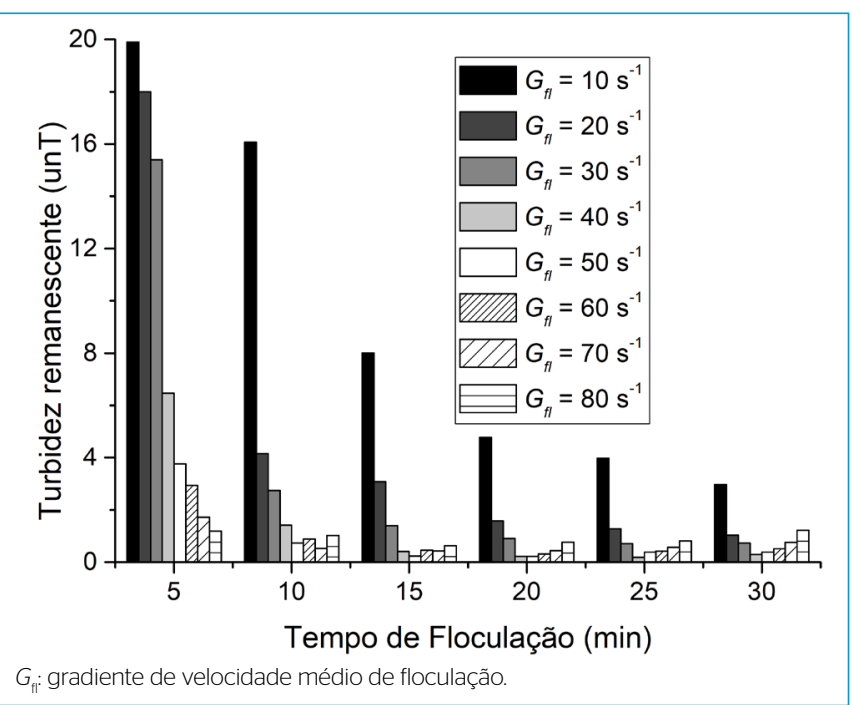

Figura 8 - Gráfico da variação da turbidez remanescente em função do tempo de floculação para diferentes gradientes de velocidade médios de floculação. 
para um $G_{\mathrm{fl}}$ de $80 \mathrm{~s}^{-1}$ serem significantemente melhores que o de $10 \mathrm{~s}^{-1}$. Porém, partículas floculadas podem se dividir em agregados menores em razão das forças de cisalhamento hidrodinâmicas (GHERNAOUT et al., 2015), o que explica o fato de no $G_{\mathrm{fl}}$ de $80 \mathrm{~s}^{-1}$ a eficiência de remoção de turbidez diminuir após 15 min de floculação. A floculação escalonada consiste na aplicação de gradiente de velocidade médio maior inicialmente, com o intuito de maximizar a frequência de colisão entre as partículas desestabilizadas, diminuindo-o posteriormente para evitar o cisalhamento acentuado dos flocos formados (DI BERNARDO; BOTARI; SABOGAL-PAZ, 2005). Usando o método de interpolação

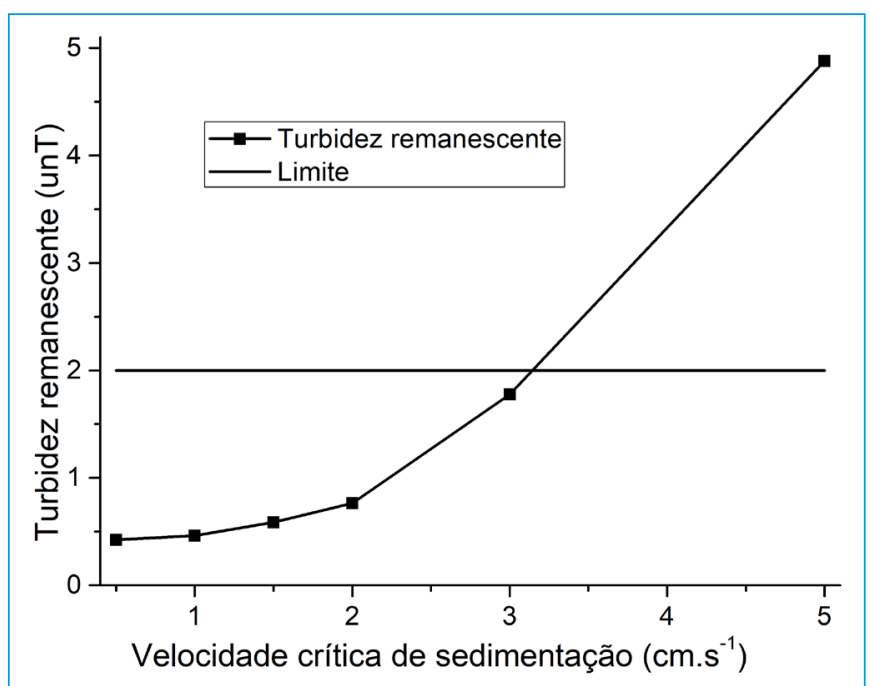

Figura 9 - Gráfico da variação da turbidez remanescente em função da velocidade crítica de sedimentação nas condições otimizadas de coagulação e floculação. proposto por Pádua (1994), a sequência de $G_{\mathrm{fl}}$ definida foi de 80-50-50 $\mathrm{s}^{-1}$, sendo o $t_{\mathrm{fl}}$, em cada $G_{\mathrm{ff}}$, de $5 \mathrm{~min}$. Determinou-se somente $15 \mathrm{~min}$ de floculação, pois após esse período teria apenas um ganho pequeno na eficiência ou se piorava a turbidez remanescente.

$\mathrm{O}$ ensaio de jar test nas condições otimizadas de mistura rápida em $1.500 \mathrm{~s}^{-1}$ por $10 \mathrm{~s}$, floculação a $80 \mathrm{~s}^{-1}$ por 5 min e $50 \mathrm{~s}^{-1}$ por $10 \mathrm{~min}$ em uma $v_{\text {cs }}$ de $0,5 \mathrm{~cm} \cdot \mathrm{s}^{-1}$ com dosagem de $30 \mathrm{mg} . \mathrm{L}^{-1}$ de PAC (1,7 mg.L $\mathrm{L}^{-1}$ de $\mathrm{Al}^{3+}$ ) e $\mathrm{pH} 7,0$, resultaram em turbidez remanescente de 0,42 unT e cor aparente remanescente de $0,8 \mathrm{uC}$, ou seja, uma redução de $79 \%$ de turbidez e $77 \%$ de cor aparente quando comparado com as condições antes da otimização da mistura rápida e da floculação.

\section{Sedimentação}

Outra forma de otimização do processo seria manter o limite de turbidez em 2,0 unT, mas aumentando a $v_{\mathrm{cs}}$. A Figura 9 exibe o gráfico construído com os resultados obtidos com diferentes $v_{c s}$,já com a coagulação e floculação otimizadas.

Na Figura 9, pode-se observar que a turbidez remanescente de 2 unT pôde ser obtida com uma $v_{\mathrm{cs}}$ de $3 \mathrm{~cm} \cdot \mathrm{s}^{-1}(2,3 \mathrm{~min})$, em vez da $v_{\mathrm{cs}}$ de $0,5 \mathrm{~cm} . \mathrm{s}^{-1}$ (14 min) antes da otimização de processo, ou seja, $500 \%$ de aumento. Esse ganho em $v_{\mathrm{cs}}$ se deve ao aumento do tamanho dos flocos formados com a otimização do processo. A Figura 10 apresenta a distribuição dos tamanhos de partícula do lodo nas condições antes e após a otimização.

Pela Figura 10, observa-se que o perfil de distribuição de tamanho dos flocos foi muito similar, mas o tamanho médio do floco médio aumentou de $22,75 \mu \mathrm{m}$ antes da otimização para $26,05 \mu \mathrm{m}$ após a

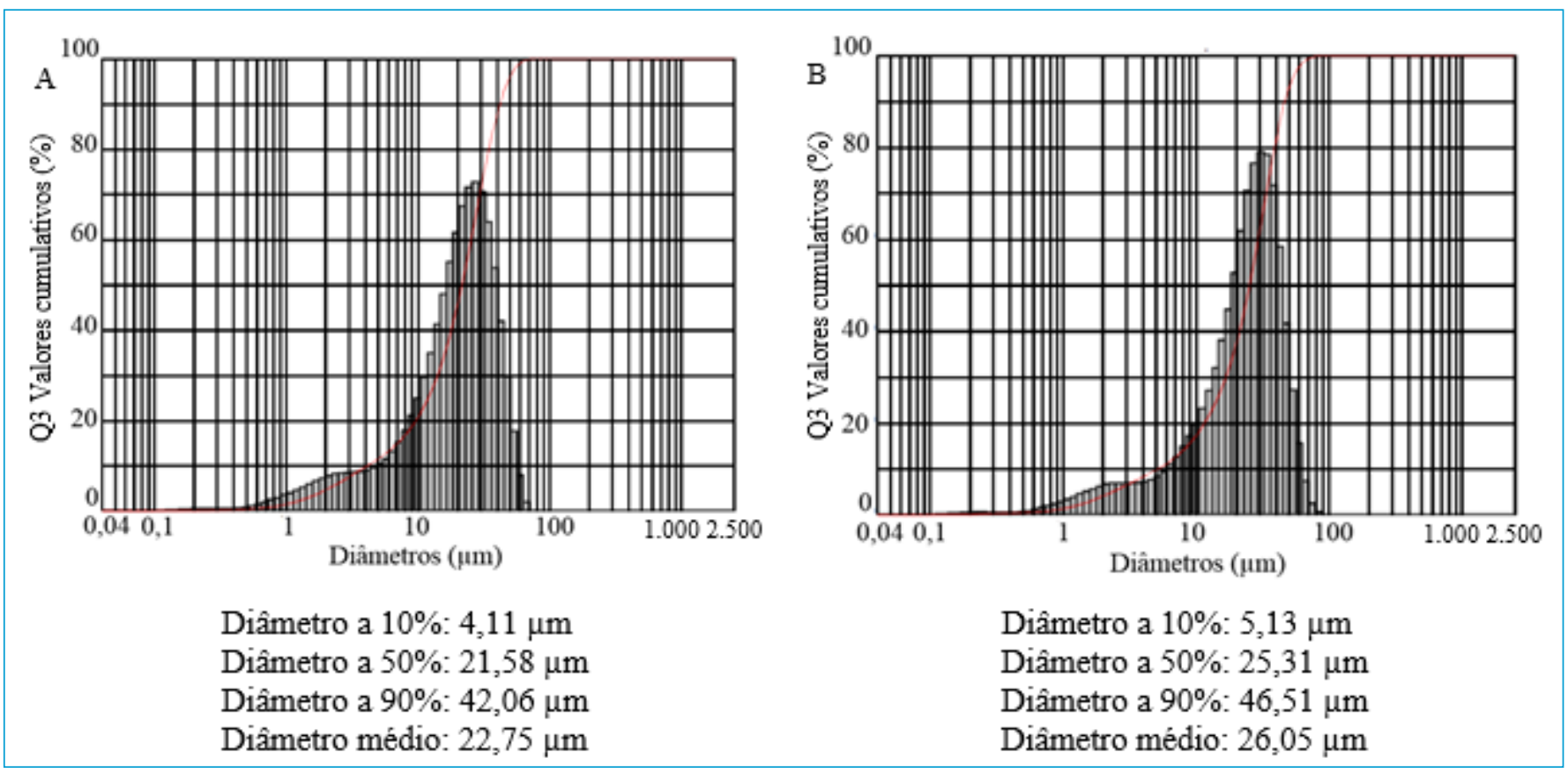

Figura 10 - Distribuição dos tamanhos de partícula do lodo nas condições (A) antes e (B) depois da otimização da coagulação e da floculação. 
otimização do processo. Em ambos os casos, porém, observa-se um aumento do tamanho da partícula comparado com a caulinita (Figura 2) de 120 a 150\%. Imagens da morfologia dos flocos são apresentadas na Figura 11.

Observa-se pela Figura 11 que a morfologia dos flocos formados nas condições antes e após a otimização são muito parecidas, porém os flocos na condição após otimização apresentam-se maiores que antes da otimização.

A $v_{\text {cs }}$ é dada pela Equação 9 (HOWE et al., 2016):

$v_{\mathrm{cs}}=\mathrm{Q} / \mathrm{A}$

Em que:

$Q=$ vazão de processo $\left(\mathrm{cm}^{3} \cdot \mathrm{s}^{-1}\right)$;

$A=$ área de sedimentação $\left(\mathrm{cm}^{2}\right)$.

Sendo assim, um aumento da $v_{\mathrm{cs}}$ de 0,5 para $3 \mathrm{~cm} \cdot \mathrm{s}^{-1}$ poderia reduzir a área do sedimentador em até 83\%.

\section{Redução da dosagem de coagulante}

Uma distinta forma de otimização do processo seria manter o limite de turbidez em 2,0 unT, mas reduzindo a dosagem de coagulante. Com a coagulação e a floculação otimizadas, mas mantendo a $v_{\mathrm{cs}}$ de $0,5 \mathrm{~cm} \cdot \mathrm{s}^{-1}$, novos ensaios jar test foram realizados com dosagens de PAC iguais ou inferiores a $30 \mathrm{mg} . \mathrm{L}^{-1}\left(1,7 \mathrm{mg} . \mathrm{L}^{-1}\right.$ de $\left.\mathrm{Al}^{3+}\right)$ até se atingir o limite de 2,0 unT. A Figura 12 ilustra tais resultados obtidos.

Analisando a Figura 12, verifica-se que, conforme já identificado na Figura 6, os resultados de turbidez remanescente foram altos para pHs inferiores a 6,5. Isso significa que otimizações de processo não são suficientes para contornar a química do coagulante, ou seja, a solubilização do precipitado amorfo de $\mathrm{Al}(\mathrm{OH})_{3}{ }^{*}$ resulta em baixa eficiência de remoção para pHs inferiores a 6,5. Porém, para pHs superiores a 6,5, a dosagem de $10 \mathrm{mg} . \mathrm{L}^{-1}$ de PAC $\left(0,6 \mathrm{mg} \cdot \mathrm{L}^{-1}\right.$ de $\left.\mathrm{Al}^{3+}\right)$ foi suficiente para se obter uma turbidez remanescente de 2,0 unT. Com isso, após otimização da coagulação e da floculação, pode-se obter uma redução de $67 \%$ na dosagem de PAC para se alcançar os mesmos resultados de turbidez remanescente. Essa redução traz benefícios econômicos e ambientais, visto que menos coagulante será empregado e menos lodo será gerado. Além disso, a dosagem de $30 \mathrm{mg} . \mathrm{L}^{-1}$ de PAC (1,7 mg. $\mathrm{L}^{-1}$ de $\left.\mathrm{Al}^{3+}\right)$ foi suficiente para se obter turbidez remanescente de $0,1 \mathrm{unT}$ e cor aparente de 2,9 uC, ou seja, atender ao Padrão de Potabilidade Brasileiro (BRASIL, 2017). Nos valores de referência, ou seja, antes da otimização, os padrões de potabilidade somente eram atingidos em dosagens superiores a 60 mg. $\mathrm{L}^{-1}$ de PAC $\left(3,4 \mathrm{mg} \cdot \mathrm{L}^{-1}\right.$ de $\left.\mathrm{Al}^{3+}\right)$.

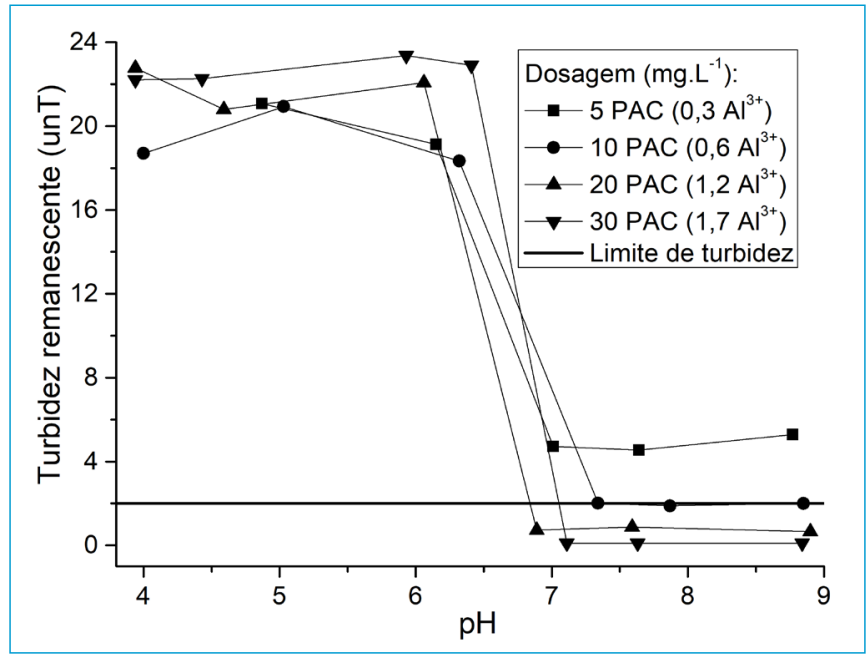

Figura 12 - Gráfico da variação da turbidez remanescente em função do $\mathrm{pH}$ em dosagens de cloreto de polialumínio iguais ou inferiores a $30 \mathrm{mg} \cdot \mathrm{L}^{-1}$ $\left(1,7 \mathrm{mg}^{-\mathrm{L}^{-1}} \mathrm{de} \mathrm{A}^{\mathrm{l}^{+}}\right)$nas condições otimizadas de coagulação e floculação.
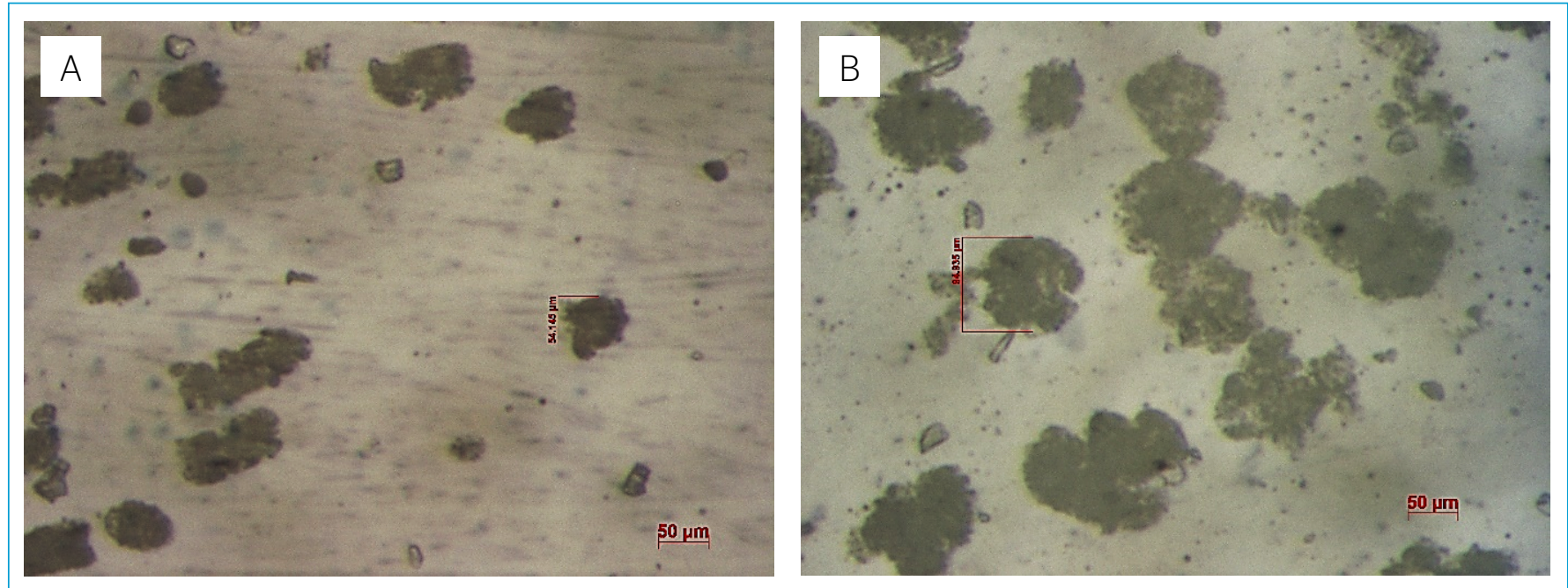

Figura 11 - Morfologia das partículas do lodo nas condições (A) antes e (B) depois da otimização da coagulação e da floculação. 


\section{CONCLUSÕES}

O estudo do emprego do PAC em estudos de tratabilidade de água de abastecimento via coagulação, floculação e sedimentação permite concluir:

- O modelamento matemático das dosagens de ácido, base, caulinita e coagulante para controle de $\mathrm{pH}$ e de turbidez da água de estudo mostrou-se uma ferramenta efetiva para a construção do diagrama de coagulação;

- $\mathrm{O}$ pH exerce forte influência na eficiência de remoção de turbidez e cor aparente, visto que o mecanismo de coagulação por varredura é determinado pela solubilidade do precipitado formado de $\mathrm{Al}(\mathrm{OH})_{3}^{*}$, que depende do $\mathrm{pH}$ e da dosagem aplicada do coagulante;

- Otimizações das operações unitárias de coagulação e floculação, desde que estejam dentro da região de $\mathrm{pH}$ e dosagem favorável do diagrama de coagulação, permitem redução do tempo de processo, diminuição da área de sedimentação, aumento da remoção de turbidez e cor aparente ou redução no consumo de coagulante. Esses resultados são alcançados em razão do aumento do tamanho do floco formado nessas etapas.

\section{REFERÊNCIAS}

BARTIKO, D; DE JULIO, M. (2015) Construção e emprego de diagramas de coagulação como ferramenta para o monitoramento contínuo da floculação em águas de abastecimento. Revista Ambiente \& Água, v. 10, n. 1, p. 71-81. https://doi.org/10.4136/ambi-agua.1239

BRASIL. (2017) Ministério da Saúde. Portaria de Consolidação no 5 (PRC5) - Anexo XX, de 28 de setembro de 2017. Brasil: Ministério da Saúde.

CARVALHO, M.S.; ALVES, B.R.R.; SILVA, M.F; BERGAMASCO, R; CORAL, L.A.; BASSETTI, F.J. (2016) $\mathrm{CaCl}_{2}$ applied to the extraction of Moringa oleifera seeds and the use for Microcystis aeruginosa removal. Chemical Engineering Journal, v. 304, p. 469-475. https://doi.org/10.1016/j. cej.2016.06.101

DI BERNARDO, L.; BOTARI, A.; SABOGAL-PAZ, L.P.S. (2005) Uso de Modelação matemática para projetos de câmaras mecanizadas de floculação em série em estações de tratamento de água. Engenharia Sanitária e Ambiental, v. 10, n. 1, p. 82-90. https://doi.org/10.1590/S141341522005000100010

DI BERNARDO, L.; DANTAS, A.D.B. (2005) Métodos e técnicas de tratamento de água. 2. ed. São Carlos: RIMA. 792 p. v. 1.

FARHADI, M; TAKDASTAN, A; BAGHBANY, R. (2016) Evaluating the Efficiency of Tragacanth Coagulant Aid in Removing Colloidal Materials and Suspended Solids Creating Turbidity from Karun River Water. Journal of Environmental Health and Sustainable Development, v. 1, n. 1, p. 1-8.

FERRARI, T.N.; DE JULIO, M.; DE JULIO, T.S.; SOUSA JÚNIOR, W.C. (2012) Estudos de Tratabilidade das Águas do Rio Paraíba do Sul que Abastecem o Município de São José dos Campos/SP. Revista AIDIS de Ingeniería y Ciencias Ambientales, v. 5, n. 2, p. 45-58. http://dx.doi. org/10.22201/iingen.0718378xe.2012.5.2.32646

FERREIRA FILHO, S.S.; WAELKENS, B.E. (2009) Minimização da produção de lodo no tratamento de águas de abastecimento mediante uso do cloreto de polialumínio e sua disposição em estações de tratamento de esgotos. Engenharia Sanitária e Ambiental, v. 14, n. 3, p. 317-326. https://doi.org/10.1590/S1413-41522009000300005

GHERNAOUT, D.; AL-GHONAMY, A.I; BOUCHERIT, A.; GHERNAOUT, B.; NACEUR, M.W.; MESSAOUDENE, N.A.; AICHOUNI, M.; MAHJOUBI, A.A.; ELBOUGHDIRI, N.A. (2O15) Brownian Motion and Coagulation Process. American Journal of Environmental Protection, v. 4, n. 5-1, p. 1-15. https://doi.org/10.11648/j.ajeps.s.2015040501.11
HENDRIKS, D. (2011) Fundamentals of Water Treatment Unit Processes: Physical, Chemical, and Biological. Boca Ratón: CRC Press. 883 p.

HOWE, K.J.; HAND, DW:; CRITTENDEN, J.C.; TRUSSELL, R.R.; TCHOBANOGLOUS, G. (2016) Princípios de tratamento de água. São Paulo: Cengage. 602 p.

PÁDUA, V.L. (1994) Metodologia para determinação dos gradientes de velocidade médios em unidades de floculação de mistura completa com câmaras em série e escoamento contínuo a partir de ensaios em reatores estáticos. 74f. São Carlos. Dissertação (Mestrado) - Escola de Engenharia de São Carlos, Universidade de São Paulo, São Carlos.

PERNITSKY, D; EDZWALD, J. (2003) Solubility of polyaluminium coagulants. Journal of Water Supply: Research and Technology, v. 52, n. 6. p. 395-406. https://doi.org/10.2166/aqua.2003.0036

PERNITSKY, D.; EDZWALD, J. (2006) Selection of alum and polyaluminum coagulants: principles and applications. Journal of Water Supply: Research and Technology, v. 55, n. 2, p. 121-141. https:// doi.org/10.2166/aqua.2006.062

RIBEIRO, J.V.M.; ANDRADE, P.V.; REIS, A.G. (2019) Moringa oleifera seed as a natural coagulant to treat low-turbidity water by in-line filtration. Revista Ambiente \& Água, v. 14, n. 6, e2442. https://doi.org/10.4136/ ambi-agua.2442

WEI, N.; ZHANG, Z.; LIU, D.; WU, Y.; WANG, J.; WANG, Q. (2O15) Coagulation behavior of polyaluminum chloride: Effects of $\mathrm{pH}$ and coagulant dosage. Chinese Journal of Chemical Engineering, v. 23, n. 6, p. 1041-1046. https://doi.org/10.1016/j.cjche.2015.02.003

YUKSELEN, M.A.; GREGORY, J. (2004) The reversibility of floc breakage. International Journal of Mineral Processing, v. 73, n. 2-4, p 251-259. https://doi.org/10.1016/SO301-7516(03)00077-2

ZHANG, Z.; WANG, J.; LIU, D.; LI, J.; WANG, X.; SONG, B.; YUE, B.; ZHAO, K.; SONG, Y. (2017) Hydrolysis of polyaluminum chloride prior to coagulation: Effects on coagulation behavior and implications for improving coagulation performance. Journal of Environmental Sciences, v. 57, p. 162-169. https://doi.org/10.1016/j.jes.2016.10.014 